\title{
Incidence of Neonatal Birth Injuries and Related Factors in Kashan, Iran
}

\author{
Masoumeh Abedzadeh-Kalahroudi ${ }^{1}$; Ahmad Talebian ${ }^{1, *}$; Mohammad Jahangiri ${ }^{1}$; Elaheh \\ Mesdaghinia ${ }^{1}$; Mahdi Mohammadzadeh ${ }^{1}$ \\ ${ }^{1}$ Trauma Research Center, Kashan University of Medical Sciences, Kashan, IR Iran \\ *Corresponding author: Ahmad Talebian, Trauma Research Center, Kashan University of Medical Sciences, Kashan, IR Iran. Tel/Fax: +98-3155620634, E-mail: talebianmd@yahoo.com
}

Received: August 17, 2014; Revised: October 18, 2014; Accepted: December 10, 2014

\begin{abstract}
Background: Birth injuries are defined as the impairment of neonatal body function due to adverse events that occur at birth and can be avoidable or inevitable. Despite exact prenatal care, birth trauma usually occurs, particularly in long and difficult labor or fetal malpresentations.

Objectives: This study aimed to investigate the incidence of birth injuries and their related factors in Kashan, Iran, during 2012-2013.

Patients and Methods: In this cross-sectional study, all live-born neonates in the hospitals of Kashan City were assessed prospectively by a checklist included demographic variables (maternal age, weight, and nationality), reproductive and labor variables (prenatal care, parity, gestational age, premature rupture of membrane (PROM), fetal heart rate (FHR) pattern, duration of PROM, induction of labor, fundal pressure, shoulder dystocia, fetal presentation, duration of second stage, type of delivery, and delivery attendance), and neonatal variables (sex, birth weight, height, head circumference, Apgar score, and neonatal trauma). Birth trauma was diagnosed based on pediatrician or resident examination and in some cases confirmed by paraclinic methods. Statistical analyses were performed by chi-square, student's t-test, and multiple logistic regression analyses using SPSS version 17.P $\leq 0.05$ was considered statistically significant.

Results: In this study, the incidence of birth trauma was $2.2 \%$. Incidence of trauma was $3.6 \%$ in vaginal deliveries and $1.2 \%$ in cesarean sections $(\mathrm{P}<0.0001)$. The most common trauma was cephalohematoma $(57.2 \%)$ and then asphyxia $(16.8 \%)$. In multiple logistic regression analyses, decreased fetal heart rate (FHR), fundal pressure, shoulder dystocia, vaginal delivery, male sex, neonatal weight, delivery by resident, induction of labor, and delivery in a teaching hospital were predictors of birth trauma.

Conclusions: Overall, incidence of birth trauma in Kashan City was lower in comparison with most studies. Considering existing risk factors, further monitoring on labor, and delivery management in teaching hospitals are recommended to prevent birth injuries. In addition, careful supervision on students and residents' training should be applied in teaching hospitals.
\end{abstract}

Keywords:Birth Injury; Incidence; Neonate; Risk Factors

\section{Background}

Birth injuries are defined as impairment of neonatal body function due to adverse events that occurs at birth and can be avoidable or inevitable. Despite exact prenatal care, birth trauma usually occurs particularly in long and difficult labor or fetal malpresentations (1). The incidence of birth trauma has decreased over time with improved obstetric care and perinatal diagnosis (2). The incidence of birth trauma varies based on type of delivery, fetal presentation, and types of injury and is reported to be between 0.2 and 41.2 per 1000 birth (3-12). It seems that the rate of neonatal trauma will never be zero because birth injury will occur in the optimal condition, best obstetrical care and diagnosis, and even in the absence of any risk factors (13). Rate of birth trauma is about $2 \%$ in normal vaginal delivery (NVD) with cephalic presentation and $1.1 \%$ in cesarean section $(C / S)(13,14)$. Birth injuries include soft tissue injuries (bruises, petechiae, subcutaneous fat necrosis, ulceration, and perforation), cephalohematoma, caput succedaneums, spontaneous intracranial hemorrhage, spinal cord injury, brachial plexus injury (Erb's palsy and Klumpke's paralysis), facial nerve palsy, musculoskeletal injury (clavicular fracture and torticollis), and hypoxic-ischemic injury (15). In most studies cephalohematoma and clavicular fracture were the most frequent birth injuries $(6,9,11)$. Moreover, there are different risk factors for birth injuries, such as instrumental delivery, gestational age at delivery, preterm rupture of membranes (PROM), academic degree of birth attendance, induction of labor, neonatal weight, height, and head circumference, prolonged labor, breech delivery, macrosomia, shoulder dystocia, maternal pelvic abnormalities, parity, and maternal age (3-11). Some studies have shown lower risk of birth trauma for C/S delivery $(5,8,11)$. Identification of birth injuries and related factors is necessary to implementing treatment procedures and determine prognosis as well as their diagnosis and use of appropriate methods of obstetric cares and timely $\mathrm{C} / \mathrm{S}$, which can prevent and reduce the prevalence of these injuries. 
Abedzadeh-Kalahroudi M et al.

\section{Objectives}

Given that studies in this area were limited and there was no study in Kashan City, this study was conducted to investigate the incidence of birth injuries and related factors in neonatal born in Kashan City during 2012-2013.

\section{Patients and Methods}

This cross-sectional study was performed prospectively on all live-born neonates in the hospitals of Kashan from September 2012 to October 2013. Kashan is located at Isfahan province in central part of Iran with population of 420000 and three maternity hospitals, including Shabihkhani, Shahid-Beheshti, and Milad. All women and their neonates with gestational age of $>28$ weeks were included in this study. Data were gathered by midwives and nurses in labor and postpartum wards using a checklist included demographic variables (maternal age, maternal weight, and nationality), reproductive and labor variables (prenatal care, parity, gestational age, PROM, duration of PROM, induction of labor, fetal heart rate (FHR) pattern, fundal pressure, shoulder dystocia, fetal presentation, duration of second stage, type of delivery, and delivery attendance), and neonatal variables (sex, birth weight, height, head circumference, Apgar score, and neonatal trauma). Birth trauma was diagnosed based on pediatric physician or resident examination. All of the diagnoses were based on full physical examination by specialists and ultrasonographic and radiologic studies.Neonatal asphyxia were Diagnosed based on clinical evidence (low Apgar score at 10 and 20 minute, need to resuscitation, hypotonia , seizure ,Acidosis) and radiological evidence(Sonography and CT scan). This study was approved by ethical committee of Kashan University of Medical Sciences and each woman signed an informed consent form.

Statistical analysis was performed using SPSS 17 (SPSS Inc., Chicago, IL, USA). Independent-sample t-test and chisquare test were used to compare respectively quantitative and qualitative variables between the two groups. Multiple logistic regression with enter method was used for determining predictors of birth trauma. $\mathrm{P}<0.05$ was considered statistically significant.

\section{Results}

This cross-sectional study was conducted during one year (2012-2013). The number of deliveries at three hospitals of Kashan was 7154. Totally, $89 \%$ of women were in the age group of 18 to 35 years, $89 \%$ were Iranian, $87.9 \%$ were under prenatal care, and 57.2\% were multipara. Moreover, $54.5 \%$ of deliveries were done by $\mathrm{C} / \mathrm{S}$ and $71.2 \%$ by obstetric resident. PROM was seen in $15.3 \%$, fundal pressure in $7.9 \%$, shoulder dystocia in $1 \%$, and decreased FHR in $6.4 \%$ of the cases. Most of deliveries (70.4\%) were performed between 38 to 40 weeks of pregnancy. Duration of second stage of labor was $<60$ minutes in $85.9 \%$ of nulliparous women and $<30$ minutes in $83.3 \%$ of multiparous women. In addition, $52.1 \%$ of neonates were male and $98.6 \%$ had the first minute Apgar score of $>7$. The birth weight of most infants (88.3\%) was between 2500 and $4000 \mathrm{~g}$. The incidence of birth trauma in our region was $2.2 \%$ or 22 cases per 1000 delivery. Birth trauma incidence was 3.6\% in NVD and 1.2\% in C/S. In this study, 161 cases of birth trauma occurred in 148 infants with isolated trauma in 135 infants and multiple traumas in 13 infants. In ten neonates, two injuries and in three neonates, three injuries were observed. Table 1 shows the type of neonatal trauma; the most common birth trauma was cephalohematoma (57.2\%), followed by asphyxia (16.8\%). Table 2 shows a significant association between incidence of neonatal injury and type of hospitals, parity, fundal pressure, shoulder dystocia, FHR drop, induction of labor, PROM, type of delivery, NVD attendance, neonatal sex, Apgar score, second stage duration, maternal weight and neonatal head circumference. All variables that were significantly associated with the trauma and variables with $\mathrm{P}<0.2$ were analyzed by logistic regression and it was found that decreased FHR, fundal pressure, shoulder dystocia, NVD, gender, neonatal birth weight, delivery by resident, induction of labor, and delivery in a teaching hospital were predictors of birth trauma (Table 3 ).

\begin{tabular}{|c|c|c|c|}
\hline Type of Injury & Number & Percentage in All Injuries & Percentage in Study Population \\
\hline \multicolumn{4}{|l|}{ Extra cranial trauma } \\
\hline cephalohematoma & 92 & 57.2 & 1.28 \\
\hline \multicolumn{4}{|l|}{ Fractures } \\
\hline Clavicular fractures & 6 & 3.7 & 0.08 \\
\hline Rib fractures & 1 & 0.6 & 0.01 \\
\hline Intracranial hemorrhage & 3 & 1.8 & 0.04 \\
\hline \multicolumn{4}{|l|}{ Neurologic trauma } \\
\hline Erb’s' palsy & 5 & 3.2 & 0.07 \\
\hline Facial palsy & 1 & 0.6 & 0.01 \\
\hline Spinal injury & 1 & 0.6 & 0.01 \\
\hline \multicolumn{4}{|l|}{ Soft tissue injury } \\
\hline Skin hematoma & 2 & 0.6 & 0.03 \\
\hline Laceration & 3 & 1.8 & 0.04 \\
\hline
\end{tabular}


Abedzadeh-Kalahroudi M et al.

\begin{tabular}{|c|c|c|c|c|c|}
\hline Ecchymosis & 17 & 10.6 & & \multicolumn{2}{|c|}{0.24} \\
\hline \multicolumn{6}{|l|}{ Face Injury } \\
\hline Eye trauma & 3 & 1.8 & & \multicolumn{2}{|c|}{0.04} \\
\hline \multicolumn{6}{|l|}{ Ischemic-Hypoxic trauma } \\
\hline Asphyxia & 27 & 16.8 & & \multicolumn{2}{|c|}{0.38} \\
\hline Total & 161 & 100 & & \multicolumn{2}{|c|}{2.2} \\
\hline \multicolumn{2}{|l|}{ Variables } & Trauma & No Trauma & P Value & OR $(95 \% \mathrm{CI})$ \\
\hline \multicolumn{2}{|l|}{ Type of hospital } & & & $<0.0001$ & $2.5(1.7-3.5)$ \\
\hline \multicolumn{2}{|l|}{ Teaching } & $117(3.2)$ & $3576(96.8)$ & & \\
\hline \multicolumn{2}{|l|}{ Non-Teaching } & $44(1.3)$ & $3433(98.7)$ & & \\
\hline \multicolumn{2}{|l|}{ Parity } & & & $<0.0001$ & $1.8(1.3-2.4)$ \\
\hline \multicolumn{2}{|l|}{ Nullipara } & $92(3)$ & $2980(97)$ & & \\
\hline \multicolumn{2}{|l|}{ Multipara } & $69(1.7)$ & $4029(98.3)$ & & \\
\hline \multicolumn{2}{|l|}{ Fundal pressure } & & & $<0.0001$ & $3.6(2.4-5.3)$ \\
\hline \multicolumn{2}{|l|}{ Yes } & $37(7.3)$ & $469(92.7)$ & & \\
\hline \multicolumn{2}{|l|}{ No } & $124(2.1)$ & $5734(97.9)$ & & \\
\hline \multicolumn{2}{|l|}{ Shoulder dystocia } & & & 0.001 & $4.6(1.2-10.3)$ \\
\hline \multicolumn{2}{|l|}{ Yes } & $7(10.4)$ & $60(89.6)$ & & \\
\hline \multicolumn{2}{|l|}{ No } & $154(2.4)$ & $6132(97.6)$ & & \\
\hline \multicolumn{2}{|l|}{ Decreased FHR } & & & $<0.0001$ & $3.1(1.9-4.6)$ \\
\hline \multicolumn{2}{|l|}{ Yes } & $27(6)$ & $421(94)$ & & \\
\hline \multicolumn{2}{|l|}{ No } & $134(2.1)$ & $6353(97.9)$ & & \\
\hline Induction of labor & & & & $<0.0001$ & $3.1(2.2-4.5)$ \\
\hline Yes & & $117(3.6)$ & $3108(96.4)$ & & \\
\hline No & & $44(1.2)$ & $3688(98.8)$ & & \\
\hline PROM & & & & $<0.0001$ & $1.9(1.4-2.8)$ \\
\hline Yes & & $42(3.8)$ & $1058(96.2)$ & & \\
\hline No & & $119(2)$ & $5951(98)$ & & \\
\hline Type of delivery & & & & $<0.0001$ & $3(2.2-4.3)$ \\
\hline NVD & & $116(3.6)$ & $3147(96.4)$ & & \\
\hline $\mathrm{C} / \mathrm{S}$ & & $45(1.2)$ & $3862(98.8)$ & & \\
\hline NVD attendance & & & & $<0.0001$ & - \\
\hline Specialist & & $5(2.1)$ & $232(97.9)$ & & \\
\hline Resident & & $59(6)$ & $917(94)$ & & \\
\hline Midwife & & $33(2.5)$ & $1264(97.5)$ & & \\
\hline Student & & $19(2.5)$ & $734(97.5)$ & & \\
\hline Neonatal sex & & & & 0.003 & $1.8(1.3-2.4)$ \\
\hline Female & & $56(1.6)$ & $3377(98.4)$ & & \\
\hline Male & & $105(2.8)$ & $3632(97.2)$ & & \\
\hline Neonatal Apgar score & & & & $<0.0001$ & - \\
\hline $0-3$ & & $9(20.9)$ & $34(79.1)$ & & \\
\hline $4-6$ & & $23(34.3)$ & $44(56.7)$ & & \\
\hline $7-10$ & & $129(1.8)$ & $6931(89.2)$ & & \\
\hline Second stage duration, min & & & & & \\
\hline Nullipara & & $48.6 \pm 32.1$ & $36.2 \pm 26.9$ & $<0.0001$ & - \\
\hline Multipara & & $27.7 \pm 28.1$ & $19.1 \pm 20.8$ & 0.047 & - \\
\hline Maternal age, $y$ & & $26.8 \pm 4.8$ & $27.7 \pm 5.3$ & 0.015 & - \\
\hline Maternal weight, kg & & $77.6 \pm 12$ & $75.2 \pm 11.8$ & 0.001 & - \\
\hline Neonatal head circumference, $\mathrm{cm}$ & & $33.7 \pm 1.9$ & $34.4 \pm 1.7$ & $<0.0001$ & - \\
\hline
\end{tabular}


Abedzadeh-Kalahroudi M et al.

Table 3. Birth Trauma Predictors Based on Logistic Regression Model a

\begin{tabular}{lcc}
\hline Predictive Variables & Adjusted OR(95\% CI) & P Value \\
\hline Decreased FHR & $0.43(0.269-0.702)$ & 0.001 \\
\hline Fundal Pressure & $0.41(0.261-0.632)$ & 0.004 \\
\hline Neonatal Male & $0.56(0.390-0.804)$ & 0.001 \\
\hline Delivery in Teaching Hospital & $2.15(1.396-3.323)$ & 0.001 \\
\hline NVD & $1.99(1.198-3.325)$ & 0.008 \\
\hline Induction of Labor & $0.51(0.331-0.804)$ & 0.004 \\
\hline Delivery by Resident & $0.44(0.252-0.777)$ & 0.005 \\
\hline Neonatal Birth Weight & $0.999(0.999-1)$ & 0.018 \\
\hline
\end{tabular}

a Abbreviations: CI, confidence interval; FHR, fetal heart rate; NVD, normal vaginal delivery; OR, odds ratio.

\section{Discussion}

The incidence of trauma in our study population was $2.2 \%$ or 22 per 1000 births (NVD and C/S). This rate of trauma was lower in our study than in others $(4,6,11,12,16)$. It can be due to a higher incidence of $C / S$, not using vacuum and forceps for delivery, and lack of NVD for breech and face presentations in maternity hospitals in Kashan City. The most common types of injuries were consecutively cephalohematoma (57.2\%) and asphyxia (16.8\%). The risk of cephalohematoma is about $1 \%$ to $2 \%$ per delivery (15). In this study, the overall incidence of cephalohematoma was $1.28 \%$ and incidence of cranial injuries, including cephalohematoma and intracranial hemorrhage in traumatic infants was $1.32 \%$, somewhat similar to many studies, such as those by Awari et al., Wark et al., and Hughes et al. $(4,11,17)$. In our study, asphyxia was the second cause of birth trauma with frequency of $16.8 \%$ and incidence of 3.8 in 1000 delivery. Many studies reported only mechanical birth injuries and did not consider asphyxia as trauma; therefore, the second cause of birth trauma was the other type of traumas such as clavicular fracture. Nevertheless, our findings were similar to those of Ghorashi et al. where $17.6 \%$ of birth injuries were due to asphyxia as a second cause of birth trauma (7). On the other hand, in Borna et al. study (6), the rate of birth asphyxia as a fourth leading cause of neonatal trauma was lower than our incidence (1.95 per 1000 live birth). High incidence of asphyxia in our study could be caused by high frequencies of the labor induction (76.7\% in NV/D and 18.4\% in C/S) and the subsequent FHR drop. Moreover, all deliveries (NVD and $C / S$ ) were reviewed in our study, but in study by Borna et al., NVDs were assessed (6). Brachial plexus injuries are the main causes of neonatal long-term complications and its rates have been reported between $0.04 \%$ to $0.2 \%$ (15). In this study, the overall incidence of brachial plexus injuries was $0.08 \%$, which was slightly lower than the rate of $0.1 \%$ reported by Awari et al. (4). The incidence of musculoskeletal injuries during childbirth varies according to different studies. The overall incidence of clavicular fracture is reported to be $0.5 \%$ to $1.6 \%(18,19)$. In this study, the overall rate of clavicular fracture was $0.08 \%$ and the rate among affected infants was 3.7\%. This rate was much lower than those reported in other studies $(4,6,8,11)$ and might be due to high rate of C/S in our maternity centers that could lead to reluctancy to perform NVD for macrosomic infants. In this study, incidence of birth trauma in vaginal deliveries was $3.6 \%$ with $59.4 \%$ of them having cranial trauma (cephalohematoma). The incidence of trauma in C/S deliveries was $1.2 \%$ and the most frequent injury was cephalohematoma (51.1\%). Other researches also determined that $\mathrm{C} / \mathrm{S}$ delivery is associated with a low risk of neonatal injury $(4,8,11,20)$ and it further emphasizes on the need for greater attention to risk factors, especially in NVDs. Reason for differences in incidence rates in our study with other studies could be due to several factors:

1) Differences in the study population; for example, in Borna et al. (6) and Linder et al. (8) studies, only cephalic singleton pregnancies were assessed while we included both $\mathrm{C} / \mathrm{S}$ and NVDs, singleton or multiple deliveries, and all types of fetal presentations.

2) Difference in research location; for example, some studies have examined only teaching hospitals $(4,6,16$, 20, 21), but in this study, all hospitals in Kashan City, including training and private, were reviewed.

3) Differences in study design; Numan et al. (21) and Borna et al. (6) studies were case-control study but our study was a cross-sectional study.

4) Different in types of trauma; in the Rezaei et al. (16) and Numan et al. (21) studies, caput succedaneum was considered as trauma and therefore, incidence of trauma was higher in these studies; on the other hand, similar to most studies (4, 6, 8-12), caput succedaneum was not considered as trauma in our work.

In this study, similar to other studies, a significant association was observed between occurrence of birth trauma and type of hospital $(12,22)$, parity $(4,8,17,21)$, shoulder dystocia $(11,16,21)$, duration of second stage of labor (21), educational degree of birth attendance $(6,22)$, PROM (6), induction of labor (6), type of delivery $(10,11,20,22)$, neonatal sex $(6,12,17)$, first minute Apgar score $(16)$, and neonatal head circumference $(6,8)$. In addition, in this study, significant association was seen between trauma and maternal age and weight, fundal pressure, and decreased FHR, while these variables were not considered in other studies and therefore, comparison could not be made. In contrast, birth trauma was correlated with some other variables such as, instrumental delivery $(6,8,11,12$, 16 ) in some studies while because of lack of forceps and vacuum deliveries in our study, such an association could not be revealed. In this study, the sex ratio was estimated at 1.9, which was higher than the ratio of 1.2 in Warke et al. and 1.4 in Adegbehingbe et al. studies $(11,22)$. This issue confirmed by logistic regression analysis that showed boys were more susceptible to birth trauma than girls were. Among these variables, logistic regression analysis showed that decreased FHR, fundal pressure, shoulder 
dystocia, NVD, male sex, neonatal birth weight, delivery by resident, induction of labor, and delivery in teaching hospitals were predictors of birth trauma. Nevertheless, it seems that birth trauma might occur during uncomplicated deliveries and neonates face a lot of pressure during passage through the birth canal, which would make them susceptible to trauma. On the other hand, factors such as birth attendance skill can also be another reason for the birth trauma.

The strength of this study was large sample size and that we reviewed prospectively all deliveries in Kashan City, while most previous studies have been retrospective and based on existing data. The limitation of this study was that we followed neonates during their stay in the hospital. In rare cases, birth trauma might be diagnosed in private clinics after hospital discharge and therefore, they were not included in our study. The incidence of birth trauma in Kashan City was similar to many studies. With regard to risk factors such as induction of labor, FHR drop, and fundal pressure, more supervision in maternity centers should be done on labor process to prevent birth injuries. Primiparous mothers should receive extra care and their risk factors should be identified. In educational maternity centers, we recommended greater supervision of teaching students and residents. Implementation of training courses to improve skills of labor attendance would help reduce the incidence of preventable birth injuries. Cohort studies are recommended for assessing longterm outcomes of infants with birth trauma. Conducting the relevant studies are recommended determine strategies for reducing birth trauma and its complications.

\section{Acknowledgements}

We would like to thank all of the midwives and nurses in Delivery and Postpartum Wards of Shabihkhani Maternity, Shahid-Beheshti, and Milad Hospitals in Kashan City.

\section{Authors' Contributions}

Study concept and design: Masoumeh Abedzadeh-Kalahroudi, Ahmad Talebian, Mohammad Jahangiri, and Elaheh Mesdaghinia. Data gathering: Mohammad Jahangiri and Masoumeh Abedzadeh-Kalahroudi. Analysis and interpretation of data: Masoumeh Abedzadeh-Kalahroudi. Manuscript Writing: Ahmad Talebian. Critical revision of the paper: Mahdi Mohammadzadeh.

\section{Funding/Support}

This study was funded and supported by Deputy of Research in Kashan University of Medical Sciences (grant No. 9128) (Kashan, Iran).

\section{References}

1. Kliegman RM, Stanton BMD, Geme JS, Schor N, Behrman RE. Nelson Textbook of Pediatrics . 19th ed: Saunders; 2011

2. Parker LA. Part 1: early recognition and treatment of birth trauma: injuries to the head and face. Adv Neonatal Care. 2005;5(6):288-97.

3. Alexander JM, Leveno KJ, Hauth J, Landon MB, Thom E, Spong $\mathrm{CY}$, et al. Fetal injury associated with cesarean delivery. Obstet Gynecol. 2006;108(4):885-90.

4. Awari BH, Al-Habdan I, Sadat-Ali M, Al-Mulhim A. Birth associated trauma. Saudi Med J. 2003;24(6):672-4.

5. Baskett TF, Allen VM, O'Connell CM, Allen AC. Fetal trauma in term pregnancy. Am J Obstet Gynecol. 2007;197(5):499 e1-7.

6. Borna H, Rad SM, Borna S, Mohseni SM. Incidence of and risk factors for birth trauma in Iran. Taiwan J Obstet Gynecol. 2010;49(2):170-3.

7. Ghorashi Z, Ahari HS, Okhchi RA. Birth injuries of neonates in Alzahra hospital of Tabriz Iran. Pakistan J Med Sci. 2013;21(3):28991.

8. Linder N, Linder I, Fridman E, Kouadio F, Lubin D, Merlob P, et al. Birth trauma-risk factors and short-term neonatal outcome. J Matern Fetal Neonatal Med. 2013;26(15):1491-5.

9. Mamouri GA, Mahmoudi E. A study of birth injuries in 6850 live-born infants. Iran J Pediatr. 1996;6(24):309-18.

10. Mosavat SA, Zamani M. The incidence of birth trauma among live born term neonates at a referral hospital in Rafsanjan, Iran. J Matern Fetal Neonatal Med. 2008;21(5):337-9.

11. Warke C, Malik S, Chokhandre M, Saboo A. Birth Injuries - A Review of Incidence, Perinatal Risk Factors and Outcome. Bombay Hosp J. 2012;54(2):202-8.

12. Sauber-Schatz EK, Markovic N, Weiss HB, Bodnar LM, Wilson JW, Pearlman MD. Descriptive epidemiology of birth trauma in the United States in 2003. Paediatr Perinat Epidemiol. 2010;24(2):11624.

13. Van Vleet M. Birth-Related Injury. In: Elzouki A, Harfi H, Nazer H, Stapleton FB, Oh W, Whitley R editors. Textbook of Clinical Pediatrics.. Berlin Heidelberg: Springer; 2012. pp.159-75.

14. Demissie K, Rhoads GG, Smulian JC, Balasubramanian BA, Gandhi K, Joseph KS, et al. Operative vaginal delivery and neonatal and infant adverse outcomes: population based retrospective analysis. BMJ. 2004;329(7456):24-9.

15. McKee Garrett TM. Neonatal birth injuries . 2013. Available from: http://www.uptodate.com/contents/neonatal-birth-injuries.

16. Rezaei M, Ghafarian SR, Balaghi IK, Hashemi H. Birth Injuries and Related Risk Factors in neonates Born in Emam Sajjad Hospital in Yasuh in 2005 - 2006. Armaghan Danesh. 2009;14(53):122-9.

17. Hughes CA, Harley EH, Milmoe G, Bala R, Martorella A. Birth trauma in the head and neck. Arch Otolaryngol Head Neck Surg. 1999;125(2):193-9.

18. Beall MH, Ross MG. Clavicle fracture in labor: risk factors and associated morbidities. J Perinatol. 2001;21(8):513-5.

19. Lam MH, Wong GY, Lao TT. Reappraisal of neonatal clavicular fracture: relationship between infant size and neonatal morbidity. Obstet Gynecol. 2002;100(1):115-9.

20. Saeedi R, Maemoori GA, Ayati S, Rahmani S, Gholami Robatsangi M. Comparison of Neonatal Complications in Newborns by Cesarean and Vaginal Delivery. J Sabzevar Univ Med Sci. 2009;16(2):108-13.

21. Numan NH, Khalid QI. Neonatal Birth Traumas: Risk factors and types. J Fac Med Baghdad. 2010;52(3).

22. Adegbehingbe OO, Owa JA, Kuti O, Olabanji JK, Adegbehingbe BO, Oginni LM. Predictive factors for birth trauma in Southwestern Nigeria. Afr J Paediatr Surg. 2007;4(1):20. 